\title{
Limitations Facing the Development of Learner Leadership in Education
}

\author{
Selma Ndeyapo Kandjengo and Elock Emvula Shikalepo
}

\section{ABSTRACT}

The Namibian Basic Education Act No. 3 of 2020 mandates schools to establish Learner Representative Councils. Learner Representative Councils are management bodies at schools comprising of learner leaders, as supporting leaders to the overall school leadership. The purpose of the study was to establish the challenges facing the development of learner leaders in schools. A case study design was used for the study, involving a school principal, teachers, and learners in Oshana Region. All participants were selected using purposive sampling technique. The data was collected using document analysis, semi-structured questionnaires, and interviews. Thematic analysis was used to analyse textual data.

The study found out that the development of learner leadership was constrained by the absence of policy directives which could drive development efforts for learner leadership. Apart from the Education Act which provides a legal framework for establishing learner leadership structures, important Regulations for enforcing and developing learner leadership were missing at the case study school. Learner leaders were also found to be influenced by peer pressure in the conduct of their leadership work. Learner leaders were not confident enough to stand by their own position and perform their leadership roles as they were afraid of losing relationship with their peers, making their peers approve most of their actions. In addition, learner leaders were finding it difficult to express themselves in English, which difficulties has lowered their confidence levels as leaders, becoming shy to express themselves as capable leaders. It becomes clear that the development of learner leaders in schools was faced by challenges that inhibited effective development of learner leaders into capable junior leaders of the school.

Keywords: Leadership, Leadership development, learner leader, Learner leadership, Learner representative council, learner voice, Management.
Published Online: July 22, 2021

ISSN: $2736-4534$

DOI : 10.24018/ejedu.2021.2.3.113

\section{S. N. Kandjengo}

Directorate of Adult Education, Ministry of Education, Arts and Culture, Namibia. (e-mail:

skadhepakandjengo@gmail.com)

E. E. Shikalepo*

Faculty of Education, The International University of Management, Namibia.

(e-mail: drshikalepo@gmail.com)

*Corresponding Author

\section{BACKGROUND OF THE STUDY}

Scholars all over the world have reported numerous challenges hampering the development of learner leadership in schools. Mitra and Gross [1] found that the communication gap existing between the school board, school administrators and learners is an obstacle to the development of learner voice and leadership in schools. Some learners in the United States of America and Australia argued that they wanted to be heard as a group, but they have shared a sense of frustration as they were being ignored collectively [2]. In addition, Smyth [2] emphasise a need for a kind of leadership in schools that fosters learner voice, as many learners were suffocating from a lack of human connection and ignorance from those who supposed to have given them a voice and be heard. There is a need for frequent interactions between learners and other members of the school and this required degree of engagement is attainable by entrusting learners with leadership roles (ibid.). Despite most schools having established Learner Representative Councils (LRC) at their schools, the councils are not functional as required and their voices are hardly heard, thus not attaining the expected performance standards. The councils need to be energised to perform optimally, but the council can only be energised if the challenges facing their operations are established and confronted.

Black et al. [3] is of the view that the hierarchical leadership model in schools could pose a challenge to developing learner leaders. The prospects for learners to participate meaningfully in the management and leadership of schools could be restricted by the hierarchical structures in which schools operate. The fact that hierarchical structures are made to accommodate ideas from top levels to bottom levels, makes it harder for school custodians to accommodate ideas from the bottom levels to top levels, excluding learner voice in the process. Hine [4] asserts that the lack of support by teachers and the misconception of staff members regarding learners' capabilities and leadership roles may 
work against the notion of learner leadership development efforts in schools.

As a result, the misconceptions and doubting of learners' capabilities can result in learner leadership failing, due to inhibited development efforts. Apart from challenges facing learner development from the school, cultural influences could also inhibit the development of learner leaders [5]. In some cultures, when adults are discussing issues that need to be resolved, children are sent away. Some cultures consider it a taboo for children to be in the presence of adults when they are engaged in a discussion of important matters.

Learners coming from the background where learners or young people are discouraged to speak out or engage with parents may find it difficult to voice their views when elected to learner leadership structures. These cultural norms could hinder learner leadership which promotes distributed leadership in schools. Therefore, it becomes clear that there are numerous challenges facing the development of established learner leadership structures in schools. In pursuit of complementing literature findings, this study sought to establish empirically, the specific factors limiting the development of learner leadership in schools, by addressing the following key research question:

- What are the factors limiting the development of learner leadership in schools?

The next section presents the methodology used for answering the above question.

\section{RESEARCH METHODOLOGY}

The methods and techniques used for the study are described according to the following outline:

\section{A. Research Design}

A qualitative research approach was used for the study, whose empirical investigation made use of a case study design, as an intensive analysis of a single phenomenon for enriched understanding of what is going on with the phenomenon being studied [6], [7]. The case study design was an ideal research design to use as the researchers intended to get intensive description of the challenges hampering the development of learner leadership in schools. Case study designs enabled researchers to acquire a comprehensive understanding of how participants relate to the subject being studied, and how they dealt with the subject of study in their specific setting [6], [8]. The interaction with different teachers and learners brought multiple perspectives of the complexity of the challenges hampering the development of learner leaders in case study schools.

Since case study help researchers set boundary for their studies [9], the researchers were able to focus on a particular, specific group of learners which was the LRC members, in addition to senior school leaders. The set boundaries helped researchers to concentrate and focus on the LRC members and the challenges they faced in getting developed into fully functional leadership entities. In addition, the flexibility inherent in case study designs [8], allowed the study to be conducted for numerous days and collected data at different times and places during the research for richer analysis and enriched understanding of the phenomenon which was studied. The flexibility also allowed researchers to use multiple sources of data and different techniques in the data gathering process, which enhanced the validity of the data collected and subsequent results.

The next section presents the research site and participants of the study.

\section{B. Sampling and Participants}

There was a total of seventeen participants in this research, comprised of twelve LRC members at the school, who were all learners and were considered the primary participants; two other learners who were class monitors and were involved in piloting the questionnaires; the School Principal, a Head of Department (HoD), and the Liaison teacher for the LRC. Purposive sampling was used as a sampling technique for the researchers to select individuals for the sample, depending on the typical characteristics that the researchers were looking for [10].

The criteria that informed sampling included leadership positions, leadership potential and the ability to provide insight into the phenomenon of the study. Purposive sampling made it possible for the researchers to choose participants who were knowledgeable of the data needed for the study [8] LRC members were chosen because they were the prime focus of the study. The School Principal and the HoD were better positioned in the school management and were thus knowledgeable of the management and leadership challenges at school in relation to the LRC. The Liaison teacher was a focal teacher to the LRC members, charged with the function of mentoring, coaching, and guiding LRC members within the school, thus knowledgeable of the challenges the LRC members were facing. The purposive nature of the sampling decisions in respect of the research site and participants enabled researchers to obtain the richest possible source of information fit for addressing the intents of the study.

The data was collected with the data collection techniques as described in the following section.

\section{Data Collection Techniques}

The data for the study was collected using document analysis, semi-structured questionnaires and interviews. The range of data collection tools was valuable for the study, as it allowed the methods to offset their respective weaknesses and capitalise on their individual strengths. The counterbalance that comes with multiple methods provided rich and meaningful data for analysis and presentation. With the permission of participants, an audio recorder and camera were used for data capturing.

The specific data collection techniques are detailed next.

\section{Document Analysis}

Document analysis is a systematic procedure for reviewing and evaluating relevant printed and electronic material for extracting information useful for answering the research questions [11]. Specific documents such as leadership files, workshop files and meeting schedules, were analysed in order to gather evident information on challenges facing learner leaders at the school. The document analysis further provided researchers with useful insights about the subject of study, which then informed the planning, designing and administration of subsequent data collection techniques. 


\section{E. Semi-structured Questionnaires}

According to Bertram and Christiansen [12], a semistructured questionnaire has a degree of open-ended questions that participants may answer as they like, in the space reserved. The purpose of the semi-structured questionnaire is to enable the researchers to standardise the questions asked, while at the same time control the amount of information that respondents provide [12]. All twelve LRC members were given the questionnaires and they provided a "written collection of self-report" based on the questions [10, p. 373]. The questions revolved around the challenges they faced in the performance of their duties as LRC members, and the development of their leadership structure.

\section{F. Individual Interviews}

Thomas [13] defines interviews as a discussion with someone from which the researcher tries to get information useful for answering the research questions. Interview is a conversation with a purpose of obtaining needed information. Interview enables participants to discuss their interpretation of the world in which they live, and to express to the researchers how they regard the situation from their own point of view [14]. Semi-structured interviews were conducted with the Liaison teacher, Head of Department and School Principal.

Interviewing teachers assisted in gathering an understanding of teachers on the challenges facing the development of learner leaders at the case study school. As the interview was used with other methods in the gathering of data, it enabled triangulation of the data collected. Furthermore, semi-structured interviews provide opportunities to ask the prepared questions according to the interview schedule, while at the same time gave the benefit of probing from participants for clarifications [13]. The interview allowed researchers to probe for detailed information on the management and leadership development of learner leaders at the case study school.

The next section describes the analysis of the data that was collected.

\section{G. Data Analysis}

Data analysis is the process of making sense of the data collected [15]. Data analysis involves the researchers conducting a data reduction process by selecting, simplifying, and transforming the raw data as gathered in the field, into manageable and meaningful data sets [12]. The data collected was analysed inductively, by establishing themes. During the inductive thematic analysis, the raw data was examined, labelled, and coded according to the responses of the respective research questions [16]. The data set were coded on sticky notes which were later pasted into a visual form for an enriched understanding of emergent findings.

The coded portions of data were then grouped logically into categories, which were constructed based on patterns and similarities emerging from data [15]. Thereafter, themes were created as research findings. After creating themes, the researchers scanned through the data again several times to look for other pertinent information missed out earlier, and that could enhance the interpretation, and in the process, more categories were formed for a richer interpretation and discussion processes [17]. The themes were interpreted and discussed by drawing useful insights from the theoretical frameworks, citing empirical evidence, and motivating the discussions with verbatim excerpts of the participants. Relating the discussion to the theories helped to validate the theoretical framework as adopted for the study, as well as confirming the correctness of the literature reviewed as it correlated with current research establishments.

The trustworthiness of the results was established through the measures described in the following section.

\section{H. Trustworthiness of Findings}

To ensure the credibility of the results, the study collected sufficient data using multiple data collection techniques and the resultant discussions provided were rigorous enough to provide convincing justifications. Two class monitors were given questionnaires prior to the main study as piloting. The piloting was done with the intention "to check for clarity and to remove ambiguities" in the data collection techniques [7, p. 402). Elimination of ambiguities in the data collection techniques means that the questions were refined and clearly understood by the respondents and correct answers were thus provided. Interviews were recorded and the participants were given an opportunity to change any wording that they felt did not capture the exactness of their words and intentions.

A very good rapport was built with the participants before the commencement of the interviews, which ensured that participants were opened to express their ideas freely to the researchers. The use of data triangulation, which is the use of multiple methods to collect data, strengthened the validity of the qualitative data [10]. The data sets were corroborated by relating findings from one data collection technique to the data collected with another technique [18]. Corroboration ensured congruence of the data, eventually producing results that draws on the strengths of individual data collection techniques as used.

\section{Ethical Considerations}

All the participants were treated with respect and dignity. The researchers explained all the details of the study to the participants so that participants were well informed with the intentions of the study, to enable them to make an informed, deliberate, and conscious decision whether to participate in the study or not. Permission to research sites was obtained. A "permission to conduct research in a school does not substitute the informed consent of parents" [19, p. 73]. Hence, informed consents were obtained from the parents and teachers as well as assenting from learners.

As the participants indicated that they wished to have their true identities concealed, pseudonyms were used for both the school and the participants in the reporting of the findings. In the reporting of the research, the interview with the liaison/mentor teacher is captured as IMT, interview with the school principal is captured as IPR, and the interview with the Head of Department is captured as IHOD. The questionnaires that were administered to respective LRC members are captured as LQ1-12. The document analysis findings are captured as DA1-7, and observations that were made by the researchers are captured as OBN1-2. Participants were informed of the confidentiality of the data and were assured that the data would not be made public and was going to be stored in a locked desk drawer and backed up as soft (digital) copies and saved on the cloud. 
The next section presents the discussions of the findings that were established.

\section{DISCUSSION OF FINDINGS}

The purpose of the study was to establish the challenges facing the development of LRC leadership structure. The data was analysed inductively, by re-reading and reviewing the collected data in view of the research questions. Ultimately, the analysis generated thematic areas as key limitations that faced efforts to develop learner leaders at the case study school. The themes relate to policy limitations, lack of confidence among LRC members, peer pressure and language barriers. The themes are discussed next.

\section{A. Policy Limitation Constrains Learner Leadership Development}

The absence of a national LRC policy constrains learner leadership development. Different participants revealed that the absence of the relevant policies was limiting the development of learner leadership at the school (IPR, IHOD \& IMT). As "there were no learner leadership development policies at the school" (IMT), it was difficulty to implement development initiative for LRC members in the absence of any guideline or policy framework. In addition to the accounts of the participants, researchers have also established that "no policy, guidelines or book guide were found on learner leadership at the school" (DA1), which could have provided direction on how to uplift learner leadership structure at school. The school "relied on the Basic Educational Act when dealing with LRC issues" (IPR \& IMT). However, the Basic Education Act is very limited in proposing development interventions for LRC development and required policy frameworks to direct the functions and development of LRC in schools. Without accompanying policies, teachers were left in limbo on how to initiate development programmes for LRC members.

The LRC members who were the focus of the study, revealed that there were "no LRC schedules or programmes for the year to guide their activities" (LQ6). The fact that there was no set year programme meant that LRC members conducted meetings and planned for any upcoming activities on an ad-hoc basis. Learners indicated that they needed a "schedule of activities for the year", to make their planning of functions and development easier (LQ7).

The issue of a lack of policies on the LRC in Namibia has been reported by earlier studies conducted by authors such as Shekupakela-Nelulu [5] and Uushona [20]. Although there were no established LRC policies, there were Regulations made under the Education Act which guides the LRC in terms of the election, nominations, power and functions [21]. The document for the Regulation was however not found at the research site as the school relied on solely on the Educational Act 16 of 2001 as a guide when dealing with LRC affairs.

The lack of policies to guide and direct learners in the Representative Council proved to be an obstacle in achieving the object of the study which is leadership development in the LRC structure. For instance, since the school does not have a copy of the Regulations made under the Education Act of 2001, the constitution of the LRC at the school consists of learners in Grade 10, 11 and 12 but the Regulations 29(c) clearly stipulates that "only a learner who will be in one of the two highest grades at the school in the following year may be nominated" for a LRC position [21, p.18].

In addition, the Regulations require that the LRC members must conduct a minimum of two meetings per term and the minutes of the meetings should be kept. However, no minutes of the LRC meetings were found at the school when documents were analysed. The absence of the policies equates to the inadequate guidance of LRC members and thus remains as a hindrance for leadership development. The possible cause of this gap regarding essential document can be attributed to the culture of the school. The unavailability of certain documents at the school might have been caused by the way the school records and stores the documents. For example, on the issue of the LRC file, it was evident that the LRC members went for training but yet no materials were found at the school site regarding the training attended. The absence of files might have spiralled from other issues, such as the school managers might not have placed value on learner leaders or recognised some of their documents as essential. Similarly, there were problems in policy dissemination from policy developers, resulting in some schools not receiving some of the important policies related to learner leadership development.

\section{B. Absence of Confidence amongst the LRC Members}

In this sub-theme, the researchers discuss the lack of confidence as a constraining factor for learner leadership development. Findings revealed that lack of confidence was caused by other aspects such as peer pressure and language barriers which are discussed later as subtheme in this section.

The findings revealed that a lack of confidence has inhibited leadership development amongst the members of the Representative Council (LQ3; LQ5; LQ6; LQ8 \& LQ9). The LRC members explained how they found it "hard to stand at the podium in order to address other learners" (JE6, p. 27). The teacher participants reiterated that the LRC members were expected to "be bold and confident, a character trait that had only been noticed in the head boy" so far (IPR). This view corresponded with findings from the researchers' observation that 'the head boy was very confident and had an aura around him that commanded respect from other LRC members" (OBN1, p. 23). In addition, one of the teachers stated that if a LRC member was not confident, other learners might not respect him/her (IHOD). Similarly, another teacher elaborated that if a LRC member lacked confidence "one can really tell you that maybe even if he or she finds other learners doing something wrong, he or she will not address them" (IPR). The above views seemed to imply that the learners might even misbehave in front of an LRC member, but the LRC member would not be able to act on it due to lack of self-confidence.

It was noted that only three members of the LRC were "really active during the first interactions with researchers" (OBN1, p. 27). The other nine members were "shy and reserved. They talked and contributed only when they were specifically asked for something. The girls were the least confident" (OBN1, p. 23).

Lack of confidence is located in the LRC members themselves. This challenge is causing the LRC members to shy away from addressing issues of other learners and 
involving themselves in other responsibilities. This serves as an impediment for the LRC growth and development in terms of leadership. The study revealed that the lack of confidence was caused by peer pressure and language barriers, whose discussion now follows.

\section{Peer Pressure Constrains Learner Leadership}

The findings pointed out that peer pressure affected the confidence of the LRC members in the school. The learners indicated that the views, behaviours, and attitudes of other learners affected their self-esteem (LQ1, LQ2 \& LQ11). One of the female LRC member said: "I am an LRC member, but my friends are not, so I have to be careful, or I will not have my friends" (LQ3). Issues of peer pressure imply that her behaviour needed to conform to her friends' behaviour, meaning her peers determined how she acted and executed her leadership role. The data concurs with the view expressed in the literature that learners at the adolescent stage are vulnerable to peer pressure, as a result they seek approval and validation from others, even at the cost of their independence just so that they can maintain relationships with their friends [22].

Peer pressure is hindering the LRC members from executing their leadership roles and from reaching the object of their mandate. Peer pressure was a social factor, hence the LRC members were either influenced or influence others. In line with this thinking, an LRC member with an uncertain social status is likely to seek acceptance from others by doing what others are doing [22]. The result of peer pressure might affect the LRC members differently, depending on the individual cultural capital.

\section{Language Barriers Dampen Confidence Levels}

The findings revealed that the confidence of the LRC members was affected by the issue of a language barrier (IPR; OBN1, p. 23; OBN2, p. 23). The findings pointed out that "the LRC members with poor English language skills were discouraged from participating in activities that needed interactions" (OBN2, p. 23). For instance, "if they pronounced a word wrongly, other learners would laugh at them and sometimes name them after that word" (OBN1, p. 23). The data concurred with the view expressed in the literature that language barriers affect confidence, and a person might avoid participating in a discussion in order to avoid a loss of face [23]. In addition, persons with a language barrier might also avoid saying something so that they might not be considered stupid, ill-informed, or slow on the uptake (ibid.). Similarly, one of the teachers interviewed felt that the "LRC members who are fluent in English talk to visitors and other learners just fine, but those that are not fluent in English find it hard to convey something to others" so they were usually reluctant to address visitors and other learners during formal gatherings (IPR).

The language barrier was limiting learners from being outspoken and from fulfilling the tasks required for leadership development. The English language as a challenge arises from history. The introduction of English as a medium of instruction in schools was made for political reasons [24]. English was never a colonial language in Namibia, thus a sudden transition to English as a medium of instruction from Afrikaans was problematic, since the majority of Namibians could not speak and/or understand the English language well
[24]. Literature emphasises that the effect of a utopian language on the learners is that they are rendered voiceless, and not able to make themselves heard in public owing to lack of command of the official language (ibid.). In essence, the LRC leadership development was probably affected by the country's historical factors related to the use of foreign languages as a medium of instruction in schools, yet not all learners were having good command of these foreign languages to be able to express themselves freely.

\section{SUMMARY}

The study attempted to establish the factors that faced the development of learner leadership in schools. An understanding of the challenges facing learner leadership could help authorities develop better interventions for addressing the plight of learner leadership development. The study found out that the development of learner leadership was mainly confronted by the absence of policy directives in schools, which rendered ineffective development of learner leaders at schools. The available Education Act was too broad to be used as an instrument to develop learner leaders as it only provides legal frameworks for establishing learner leadership structures. Appropriate Regulations and policy directives were not available at school, making it difficult for school authorities and learner leaders to map out development interventions. Clear directives could have provided guidance on how to develop learner leaders at school.

The development of learner leadership was also faced by the lack of self-confidence among LRC members. The lack of self-confidence was caused by the dependence of LRC members on their peers for validation and approval in whatever activities they were involved in. It was thus possible that LRC members were failing to develop due to dependence on other learners for direction in order to keep relationship with them. Learners were not confident enough to stand on their own on what to do as per the mandate of the learner leadership structure. In addition, the lack of self-confidence was also caused by the poor command of English as a medium of instruction and a language of communication at school. Those LRC members who were not fluent in the command of the language felt shy and not free to express themselves to others, thus inhibiting their leadership potentials.

\section{REFERENCES}

[1] Mitra, D. L. \& Gross, S. (2009). Increasing student in high school reform: Building partnership, improving outcomes. Educational Management Administration \& Leadership, 37(4), 522-543.

[2] Smyth, J. (2006). Educational leadership that foster student voice. International Journal of Leadership in Education: Theory and Practice, 9(4), 279-284.

[3] Black, R., Walsh, L., Magee, J., Hutchins, L., Berman, L. \& Groundwater-Smith, S. (2014). Student leadership: a review of effective practice. Canberra: ARACY.

[4] Hine, G. (2011). Exploring the development of student leadership potential within a catholic school: a qualitative case study. University of Notre Dame. Australia, Research online @ ND

[5] Shekupakela-Nelulu, R. (2008). An investigation into the role of student participation in school governance: A Namibian perspective. Unpublished Master's thesis. Rhodes University, Grahamstown.

[6] Simons, H. (2009). Case study research in practice. London: SAGE Publications. 
[7] Cohen, L., Manion, L., \& Morrison, K. (2011). Research methods in education $\left(7^{\text {th }}\right.$ ed.). New York: Routledge.

[8] Maree, K. (2007). First steps in research. Pretoria: Van Schaik Publishers.

[9] Berg, B. L. (2001). Qualitative research methods for social sciences ( $4^{\text {th }}$ ed. $)$. Boston: Allyn \& Bacon.

[10] Gay, L., Mills, G. \& Airasian, P. (2009). Educational research: competencies for analysis and applications. London: Pearson.

[11] Bowen, G. (2009). Document analysis as a qualitative research method. Qualitative Research Journal, 9(2), 27-40.

[12] Bertram, C. \& Christiansen, L. (2014). Understanding research: An introduction to reading research. Pretoria: Van Schaik Publishers.

[13] Thomas, G. (2009). How to do your research project. Los Angeles: Sage Publications.

[14] Cohen, L., Manion, L. \& Morrison, K. (2000). Research methods in Education (5 $5^{\text {th }}$ ed.). London: Routledge.

[15] Merriam, S. (1998). Qualitative research and case study applications in education. San Francisco: Jossey-Bass.

[16] Rule, P. \& John, V. (2011). Interpreting the case \& presenting the data: Your guide to case studies. Pretoria: Van Schaik Publishers.

[17] Lichtman, M. (2014). Qualitative research for the social sciences. Los Angeles: Sage Publications.

[18] Van der Mescht, H. (2002). Four levels of rigour in interpretive qualitative research. Education as Change, 6(1), 45-51.

[19] Wassenaar, D. R. (2007). Ethical issues in social research. In M.T. Blanche, K. Durrheim, \& D. Painter (Eds.), Research in practice: Applied methods for social sciences ( $2^{\text {nd }}$ ed.) (pp. 60-79). Cape Town: University of Cape Town Press.

[20] Uushona, A.B. (2012). Learners' participation in leadership: A case in a secondary school in Namibia. Unpublished Master's thesis. Rhodes University, Grahamstown.

[21] Namibia. Ministry of Education and Culture. (2001). Education Act No 16 of 2001.Windhoek: Government of Republic of Namibia.

[22] Allan, J., Porter, M., \& McFarland, C. (2006). Leader and followers in adolescent close friendships: susceptibility to peer influence as a predictor of risky behaviour, friendship instability and depression. Development and Psychopathology, 18, 155-170.

[23] Harzing, A., \& Freely, A. (2007). The language barrier and its implication for HG-subsidiary relations. Cross-cultural management: An International Journal, 15(1), 49-60.

[24] Tötemeyer, A-J. (2010). Multilingualism and the language policy for Namibian schools. PRAESA Occasional papers NO.37. University of Cape Town.

[25] Borg, S. (2001). The research journal: a tool for promoting and understanding researcher development. Language Teaching Research, 5(2), 156-177.

[26] Chavez, C. (2008). Conceptualizing from inside: advantages, complications and demands on insider positionality. The Qualitative Report, 13(3), 474-494.

[27] Christie, P. (2010). Landscapes of leadership in South Africa. Educational Management \& Leadership, 38(6), 694-711.

[28] de Villiers, E. (2010). Teacher leadership: Perspectives, perceptions and readiness of educators in the Eden and Central Karoo education district in the Western Cape Province. Unpublished Master's thesis. UNISA, South Africa.

[29] Fielding, M. (2004). New wave student voice and renewal of civic society. London Review of Education, 2(3), 197-217.

[30] Gillies, D. (2013). Educational leadership and Michael Foucault. New York: Routledge.

[31] Grant, C. (2008). We did not put our pieces together: Exploring a professional development initiative through a distributed leadership lens. Journal of Education, 44, 85-107.

[32] Grant, C. (2015). Invoking learners' voice and developing leadership: What matters to learners? Journal of Education, 61, 93-113.

[33] Grant, C. \& Nekondo, L. (2016). Learners as leaders in Namibian schools: Taking responsibility and exercising agency. Namibia CPD Journal for Educators, 3(1), 13-29.

[34] Gronn, P. (2000). Distributed properties: a new architecture for leadership. Educational Management Administration \& Leadership, 28(3), 317-338.

[35] Hartley, D. (2007). The emergence of distributed leadership in education why now? British Journal of Education Studies, 55(2), 202214.

[36] Hermalin, B. (1998). Toward an economic theory of leadership, leading by example. The American Economic Review, 88(5), 1188-1206.

[37] Janesick, V. (1999). A journal about journaling: Writing as a qualitative research technique history issues and reflections. Qualitative Inquiry, 5(4), 505-524.
[38] John. W. C. (2014). Educational research: Planning, conducting and evaluating quantitative and qualitative research (4th ed.). London: Pearson.

[39] Johnson. B. \& Christensen. L. (2012). Educational research: quantitative, qualitative and mixed approaches. Los Angeles: Sage Publications.

[40] Knott-Craig, I. D. (2007). An investigation of student leadership in an independent school in the Eastern Cape. Unpublished Master's Thesis. Rhodes University, Grahamstown.

[41] Mason, J. (2002). Qualitative researching ( $2^{\text {nd }}$ ed.). London: Sage Publications.

[42] Mitra, D. L. (2007). Student voice in school reform: from listening to leadership. In D. Thiessen \& A. Cook-Sather (Eds.), International Handbook of student experience in elementary and secondary school (pp. 727-744). Dordrecht, Netherlands: Springer Publishers.

[43] Shatilova, I. (2014). How students' voice can be heard in the finish context: The case of primary, lower secondary upper secondary schools in Jyvaskyla. Unpublished Master's thesis. University of Jyvaskyla, Jyvaskyla.

[44] Spillane, J. P. (2006). Distributed leadership. San Francisco: JosseyBass.

[45] Tng, C. S. (2009). An educational leadership framework based on traditional and contemporary leadership theories. E-Reader Kuala Lumpur, 1-7.

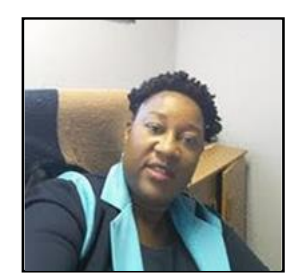

Selma Ndeyapo Kandjengo is a Senior Education Officer at the Ministry of Education, Arts and Culture. She holds a Master of Education in Educational Leadership and Management from Rhodes University, South Africa. She worked in various secondary schools as a Teacher and Head of Department. She has interests in leadership and management, training and development, adult education, and online education.

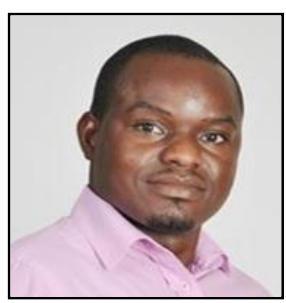

Elock Emvula Shikalepo is a Namibian academic and researcher, working at The International University of Management Namibia. He holds both graduate and postgraduate qualifications in teaching, education law, systems, and management. He obtained his Doctor of Philosophy from the University of South Africa, focusing on staff motivation and performance in the education sector. His thesis evaluated the influence of financial incentive on teacher motivation and learner performance in Namibian rural schools. He has researched widely and published extensively in the areas of education legislations, technical, vocational education, and training, teaching, and learning, management and leadership, open and lifelong learning, research supervision and publication. 